\title{
Plasmodium vivax malaria elimination: should innovative ideas from the past be revisited?
}

\author{
Fernando Fonseca Val' ${ }^{1,2}$, Vanderson Souza Sampaio ${ }^{1,2}$, Maria Belén Cassera ${ }^{3}$, \\ Raquel Tapajós Andrade ${ }^{1,2}$, Pedro Luiz Tauil ${ }^{4}$, Wuelton Marcelo Monteiro ${ }^{1,2}$, \\ Marcus Vinícius Guimarães Lacerda ${ }^{1,2} /+$
}

\begin{abstract}
${ }^{1}$ Gerência de Malária, Fundação de Medicina Tropical Dr Heitor Vieira Dourado, Manaus, AM, Brasil ²Escola Superior de Ciências da Saúde, Universidade do Estado do Amazonas, Manaus, AM, Brasil ${ }^{3}$ Department of Biochemistry, Virginia Tech Center for Drug Discovery, Virginia Tech, Blacksburg, VA, USA ${ }^{4}$ Faculdade de Medicina, Universidade de Brasília, Brasília, DF, Brasil
\end{abstract}

In the 1950s, the strategy of adding chloroquine to food salt as a prophylaxis against malaria was considered to be a successful tool. However, with the development of Plasmodium resistance in the Brazilian Amazon, this control strategy was abandoned. More than 50 years later, asexual stage resistance can be avoided by screening for antimalarial drugs that have a selective action against gametocytes, thus old prophylactic measures can be revisited. The efficacy of the old methods should be tested as complementary tools for the elimination of malaria.

Key words: malaria - Plasmodium - elimination - control - antimalarials - salt

Recent numbers from the World Health Organization (WHO) demonstrate the importance of malaria in the global scenario. In the 2013 World Malaria Report, the number of malaria cases exceeded 200 million, with 627,000 deaths (WHO 2013). These numbers have been fluctuating over recent decades, but in most endemic areas, no real possibility of elimination is expected in the next few years without envisioning new tools.

For reducing malaria transmission (i.e., malaria control), a successful programme should focus on several aspects, including early diagnosis, vector control and the use of effective antimalarial drugs. However, these strategies need to be emphasised in the elimination scenario (Tauil 2011). Moreover, searching for each individual case of malaria is a priority in the context of achieving zero reported cases (malERA 2011). In this context, tools such as mass drug administration (MDA) and mass screening and treatment (MSAT) should be considered. However, other than unpublished experiences of individual malaria control programmes, there is a lack of robust evidence supporting the efficacy of specific tools for malaria control and elimination.

Gametocyte stages are non-replicating forms that are responsible for the transmission of the malaria parasite to the mosquito vector. In contrast to other species of Plasmodium, Plasmodium falciparum gametocytes develop through five morphologically distinct stages (I to $\mathrm{V}$ ) and require 10-12 days to fully mature into stage

doi: $10.1590 / 0074-0276140240$

+ Corresponding author: marcuslacerda.br@gmail.com

Received 9 July 2014

Accepted 25 July 2014
V gametocytes (Lobo \& Kumar 1998, Baker 2010, Bousema \& Drakeley 2011). Seven days after the onset of clinical symptoms, only mature stage $\mathrm{V}$ gametocytes can be identified in the peripheral blood circulation of an infected patient and these gametocytes can persist for weeks in the circulating blood (Smalley \& Sinden 1977). Immature or early stage gametocytes (stages I to III) are often sensitive to shizonticidal drugs (Sinden \& Smalley 1979, Delves 2012, Delves et al. 2012) and circulating mature stage $\mathrm{V}$ gametocytes are sensitive to doses of primaquine (PQ) as low as $0.25 \mathrm{mg} / \mathrm{kg}$ (WHO 2012). On the contrary, Plasmodium vivax gametocytes are present at the beginning of the infection, but only live in the blood for a few days (Bousema \& Drakeley 2011). These biological differences between $P$. falciparum and $P$. vivax gametocytes suggest that the latter is more likely to maintain transmission to the vector before a proper diagnosis and treatment. Once chloroquine (CQ) or any other artemisinin-based combination therapy (ACT) is initiated, gametocytes (Douglas et al. 2012) and young trophozoites that are committed to gametocytogenesis are killed (Nosten 2010). Therefore, the discovery of $P$. vivax anti-gametocytocidal drugs has not been a priority in malaria control and elimination efforts. However, any therapeutic strategy that intends to kill $P$. vivax gametocytes before treatment is initiated represents an innovative method of controlling $P$. vivax transmission.

In 2000, the United Nations established the Millennium Declaration, which aimed to halt and then reverse "the scourge of malaria" by 2015 (UN 2000). In 2007, the WHO published a manual with guidelines for malaria elimination (WHO 2007), creating renewed attention and interest in the field. Since the manual's publication, the major achievements and failures of the Italian Malaria Eradication Campaign from the 1950s have been reconsidered. Many innovative strategies during the 
Italian campaign, including DDT spraying, focused on vector control (Majori 2012), but the addition of antimalarials to daily consumed food received special attention. At the beginning of the 1950s, Mário Pinotti, a Brazilian pharmacist and physician, proposed the addition of CQ to food salt as a novel chemoprophylaxis against malaria (Pinotti 1953). While pyrimethamine was initially used, CQ was eventually selected because of pyrimethamine's high toxicity. At that time, both $P$. falciparum and $P$. vivax were sensitive to $\mathrm{CQ}$, which is safe for human consumption (Coatney et al. 1958). On other continents, successful trials using a weekly dose of CQ supported the proposed strategy (Clyde 1966, Giglioli et al. 1967, Hall \& Wilks 1967, Motabar et al. 1971). During the same decade, similar experiments were successfully conducted in hospitals and in field conditions in Brazil (Pinotti 1954, 1959, Pinotti et al. 1955a, b, Soares 1955, Pinotti \& Soares 1956). A major problem with CQ-enriched salt was precipitation under conditions of high humidity and temperatures in the endemic areas, which left most of the active compound at the bottom of the packages. As a result of its strong bitterness, many people discarded the supplemented salt before a sufficient amount of the drug was consumed (PL Tauil, unpublished observations); insufficient consumption of drugs is a known risk factor for the development of drug resistance. For this reason, after the first trial, Pinotti was concerned about the possibility of antimalarial resistance, which manifested years later in P. falciparum (da Silva \& Hochman 2011). This result was crucial for abandoning this strategy. More recently, P. vivax has also developed resistance to CQ in the Amazon (Alecrim et al. 1999, Santana Filho et al. 2007).

Currently, strategies such as MDA with low doses of PQ are a realistic tool for eliminating malaria in areas where P. falciparum is a major problem. However, even in areas where malaria control is effective, $P$. vivax becomes a major problem because of frequent relapses and insufficient attention to the potential gametocyte carriers. Therefore, the development of a drug that kills $P$. vivax gametocytes before the beginning of treatment could be a useful tool in controlling the transmission of this parasite. An innovative approach for malaria elimination would be the reintroduction of chemoprophylaxis by enriching food salt with a drug that is active exclusively against gametocytes, thereby avoiding the selection of resistant asexual stages against routinely used antimalarials. For a chemoprophylactic strategy, the ideal drug should be (i) efficacious exclusively against gametocytes (to avoid cross-resistance with asexual stages), (ii) nontoxic to humans at the recommended dosages, (iii) stable under environmental and cooking temperatures, (iv) capable of maintaining the original organoleptic characteristics of the food and (v) safe in glucose-6-phosphate dehydrogenase (G6PD)-deficient populations.

PQ is currently available at low doses and tafenoquine, a new 8-aminoquinoline drug that is derived from PQ, and has a prolonged half-life, currently undergoing Phase III trials as an antirelapse drug (Llanos-Cuentas et al. 2013). These drugs are viable options for a chemoprophylactic strategy, however not safe for G6PD-deficient populations.
The identification of potential inhibitors of $P$. falciparum transmission has increased in recent years due to improvement in culture techniques. To catalyse the development of new antimalarials, Medicines for Malaria Venture (MMV) and SCYNEXIS assembled the Malaria Box (Spangenberg et al. 2013), an open access library of 400 compounds. The compounds were originally identified from phenotypic screening against $P$. falciparum asexual stages using over four million compounds from the research libraries of Saint Jude Children's Research Hospital, Novartis and GlaxoSmithKline (Guiguemde et al. 2012). Laboratories around the world have taken the lead by testing these compounds against the late stages of P. falciparum gametocytes (Duffy \& Avery 2013, Bowman et al. 2014, Sun et al. 2014). Compounds that appear to be specific against gametocytes have been identified and these compounds can potentially serve as starting points for the development of inhibitors that exclusively kill gametocytes. However, the selection of hit-to-lead compounds from multistage approaches is typically based on activity against both asexual and sexual stages, thereby providing less attention to agents that are only active against gametocytes. Although further investigation is required to discover more suitable leads for the proposed chemoprophylactic strategy, the concept itself may reopen an avenue to aid malaria elimination efforts. These efforts may also include drugs that have a newly recognised action against malaria vectors, such as ivermectin, the safety of which was confirmed by the administration of millions of doses in MDA efforts for other neglected diseases (Chaccour et al. 2013).

\section{REFERENCES}

Alecrim MGC, Alecrim W, Macêdo V 1999. Plasmodium vivax resistance to chloroquine (R2) and mefloquine (R3) in Brazilian Amazon Region. Rev Soc Bras Med Trop 32: 67-68.

Baker DA 2010. Malaria gametocytogenesis. Mol Biochem Parasitol 172: 57-65.

Bousema T, Drakeley C 2011. Epidemiology and infectivity of Plasmodium falciparum and Plasmodium vivax gametocytes in relation to malaria control and elimination. Clin Microbiol Rev 24: 377-410.

Bowman JD, Merino EF, Brooks CF, Striepen B, Carlier PR, Cassera MB 2014. Antiapicoplast and gametocytocidal screening to identify the mechanisms of action of compounds within the Malaria Box. Antimicrob Agents Chemother 58: 811-819.

Chaccour CJ, Kobylinski KC, Bassat Q, Bousema T, Drakeley C, Alonso P, Foy BD 2013. Ivermectin to reduce malaria transmission: a research agenda for a promising new tool for elimination. Malar J 12: 153.

Clyde DF 1966. Suppression of malaria in Tanzania with the use of medicated salt. Bull World Health Organ 35: 962-968.

Coatney GR, Mickelsen O, Burgess RW, Young MD, Pirkle CI 1958. Chloroquine or pyrimethamine in salt as a supressive against sporozoite-induced vivax malaria (Chesson strain). Bull World Health Organ 19: 53-67.

da Silva R, Hochman G 2011. A method called Pinotti: medicated salt, malaria and international health (1952-1960). Hist Cienc Saude Manguinhos 18: 519-543.

Delves MJ 2012. Plasmodium cell biology should inform strategies used in the development of antimalarial transmission-blocking drugs. Future Med Chem 4: 2251-2263. 
Delves MJ, Plouffe D, Scheurer C, Meister S, Wittlin S, Winzeler EA, Sinden RE, Leroy D 2012. The activities of current antimalarial drugs on the life cycle stages of Plasmodium: a comparative study with human and rodent parasites. PLoS Med 9: e1001169.

Douglas NM, John GK, von Seidlein L, Anstey NM, Price RN 2012. Chemotherapeutic strategies for reducing transmission of Plasmodium vivax malaria. Adv Parasitol 80: 271-300.

Duffy S, Avery VM 2013. Identification of inhibitors of Plasmodium falciparum gametocyte development. Malar J 12: 408.

Giglioli G, Rutten FJ, Ramjattan S 1967. Interruption of malaria transmission by chloroquinized salt in Guyana with observations on a chloroquine-resistant strain of Plasmodium falciparum. Bull World Health Organ 36: 283-301.

Guiguemde WA, Shelat AA, Garcia-Bustos JF, Diagana TT, Gamo F-J, Guy RK 2012. Global phenotypic screening for antimalarials. Chem Biol 19: 116-129.

Hall SA, Wilks NE 1967. A trial of chloroquine-medicated salt for malaria suppression in Uganda. Am J Trop Med Hyg 16: 429-442.

Llanos-Cuentas A, Lacerda MV, Rueangweerayut R, Krudsood S, Gupta SK, Kochar SK, Arthur P, Chuenchom N, Möhrle JJ, Duparc S, Ugwuegbulam C, Kleim J-P, Carter N, Green JA, Kellam L 2013. Tafenoquine plus chloroquine for the treatment and relapse prevention of Plasmodium vivax malaria (DETECTIVE): a multicentre, double-blind, randomised, Phase $2 \mathrm{~b}$ dose-selection study. Lancet 383: 1049-1058.

Lobo CA, Kumar N 1998. Sexual differentiation and development in the malaria parasite. Parasitol Today 14: 146-150.

Majori G 2012. Short history of malaria and its eradication in Italy with short notes on the fight against the infection in the Mediterranean Basin. Mediterr J Hematol Infect Dis 4: e2012016.

Motabar M, Mofidi C, Saebi A, Ghiassedin M, Rouhani F 1971. A medicated salt project in the Kazeroun area, Iran - 1962-1967. J Trop Med Hyg 74: 39-44.

Nosten F 2010. Waking the sleeping beauty. J Infect Dis 202: 1300-1301.

Pinotti M 1953. Chemoprophylaxis of malaria by the association of an antimalarial drug to the sodium chloride used daily in the preparation of meals. In V Congresso Internacional de Medicina Tropical e Malária, 28 Aug/4 Sep 1953, Istambul.

Pinotti M 1954. New method of malaria prevention: combination of an antimalarial drug with table salt used daily in food. Rev Bras Malariol Doencas Trop 6: 5-12.

Pinotti M 1959. The addition of antimalarial drugs to cooking salt: its importance in malaria eradication programmes. Triangle 4: $110-113$.
Pinotti M, Lobo AG, Damasceno G, Soares R 1955a. Field tests of chloroquin-table salt mixture. Rev Bras Malariol Doencas Trop 7: 5-23.

Pinotti M, Soares R 1956. Eradication of malaria with chloroquine added to table salt. Rev Bras Malariol Doencas Trop 8: 253-265.

Pinotti M, Soares R, Monte R, Paulini E, Vinha C 1955b. Tests of chloroquine-table salt mixture in hospitalized patients. Rev Bras Malariol Doencas Trop 7: 25-36.

Santana Filho FS, Arcanjo ARL, Chehuan YM, Costa MR, MartinezEspinosa FE, Vieira JL, Barbosa MGV, Alecrim WD, Alecrim MGC 2007. Chloroquine-resistant Plasmodium vivax, Brazilian Amazon. Emerg Infect Dis 13: 1125-1126.

Sinden RE, Smalley ME 1979. Gametocytogenesis of Plasmodium falciparum in vitro: the cell-cycle. Parasitology 79: 277-296.

Smalley ME, Sinden RE 1977. Plasmodium falciparum gametocytes: their longevity and infectivity. Parasitology 74: 1-8.

Soares R 1955. Study of salt-chloroquine and follow-up program in hospitalized malaria patients. Rev Bras Malariol Doencas Trop 7: 281-303.

Spangenberg T, Burrows JN, Kowalczyk P, McDonald S, Wells TNC, Willis P 2013. The open access malaria box: a drug discovery catalyst for neglected diseases. PLOS ONE 8: e62906.

Sun W, Tanaka TQ, Magle CT, Huang W, Southall N, Huang R, Dehdashti SJ, McKew JC, Williamson KC, Zheng W 2014. Chemical signatures and new drug targets for gametocytocidal drug development. Sci Rep 4: 3743.

Tauil PL 2011. The prospect of eliminating malaria transmission in some regions of Brazil. Mem Inst Oswaldo Cruz 106 (Suppl. I): 105-106.

malERA - Consultative Group on Basic Science and Enabling Technologies 2011. A research agenda for malaria eradication: basic science and enabling technologies. PLoS Med 8: e1000399.

UN - United Nations 2000. United Nations Millennium Declaration. In resolution adopted by the General Assembly, UN, New York, p. A/RES/55/2.

WHO - World Health Organization 2007. Malaria Elimination. A field manual for low and moderate endemic countries, WHO, Geneva, $98 \mathrm{pp}$.

WHO - World Health Organization 2012. WHO Evidence Review Group: the safety and effectiveness of single dose primaquine as a $P$. falciparum gametocytocide. Proceedings of the Malaria Policy Advisory Committee Meeting, 13-15 Aug 2012, Bangkok, Thailand, WHO, Geneva, 19 pp.

WHO - World Health Organization 2013. World malaria report 2013, WHO, Geneva, 284 pp. 